\title{
Phase shifter based on photonic liquid crystal fiber
}

\author{
Marzena M. Tefelska, ${ }^{1}$ Sławomir Ertman, ${ }^{1}$ Tomasz R. Woliński, ${ }^{1}$ Roman Dąbrowski, ${ }^{2}$ Jan Wójcik $^{3}$ \\ ${ }^{1}$ Faculty of Physics, Warsaw University of Technology, Koszykowa 75, 00-662 Warszawa, \\ ${ }^{2}$ Military University of Technology, Warszawa, Poland \\ ${ }^{3}$ Maria Curie Sklodowska University, Lublin, Poland
}

Received September 16, 2010; accepted September 22, 2010; published September 30, 2010

\begin{abstract}
This paper describes polarization phenomena occurring in photonic liquid crystal fibers (PLCF). The latest experimental results of a phase modulator based on photonic crystal fiber filled with liquid crystals are presented. The main goal of this experiment is to achieve a smooth change of the phase delay between orthogonal components of a mode in the range from 0 tо 2 л. This kind of phase modulators can be used in new generation polarization controllers.
\end{abstract}

In the last few years photonic crystal fibers (PCFs) have been intensively investigated by many researchers all over the world [1-3]. These fibers with diameters of the order of a few micrometers and a regular structure of micro-holes have very attractive and unique optical properties. In PCFs the light is guided by two mechanisms. The first one is based on the modified total internal reflection (mTIR) phenomenon, which is well known and is similar to wave guiding within a conventional fiber. The other, known as the photonic band gap (PBG) effect, occurs when the refractive index of the fiber core is lower than the averaged effective refractive index in the cladding region. The properties of PCFs can be modified by filling their micro holes with liquid crystals (LC) whose optical properties can be dynamically modified due to the fact that both refractive indices of LCs strongly depend on temperature and can be changed by external electric, magnetic and optical fields. These kinds of structures are called photonic liquid crystal fibers (PLCFs) [4-6]. Since 2003 there have been published a lot of papers devoted to PLCFs and their potential applications in photonics - see Ref. [4-11].

In this paper initial experimental results of a phase modulator based on photonic crystal fibers filled with special liquid crystals are presented. The special liquid crystals used in this experiment are the 1800B LC described in [11] and a new 1550A LC mixture (obtained by doping the 1550 with propyl propenylbicyclohexane). The $1550 \mathrm{LC}$ was presented in [12] and it is characterized by $\mathrm{n}_{\mathrm{e}}=1.5276, \mathrm{n}_{\mathrm{o}}=1.4618$ for $\lambda=589 \mathrm{~nm}$ at $20^{\circ} \mathrm{C}$. The $1550 \mathrm{~A}$ is characterized by $\mathrm{n}_{\mathrm{e}}=1.532, \mathrm{n}_{\mathrm{o}}=1.4655$ at $20^{\circ} \mathrm{C}$ for $\lambda=589 \mathrm{~nm}$. Its birefringence is very similar to 1550 but it crystallizes at lower temperatures.

The most important feature of the 1800B LC is that it has a low birefringence and in a wide range of a nematic phase $\left(20^{\circ} \mathrm{C}-71.5^{\circ} \mathrm{C}\right)$ ordinary refractive index $\mathrm{n}_{\mathrm{o}}$ is below the refractive index of fused silica $n_{\text {silica }}=1.458$ (at $\lambda=588 \mathrm{~nm}$ ) while its extraordinary index is still higher than $\mathrm{n}_{\text {silica }}$ (Fig. 1b). In this combination of PCF and LC the light is guided by mTIR mechanism in a very wide range of temperature. The $1550 \mathrm{~A}$ is a special modified LC wherein the propagation by mTIR mechanism occurs at an even lower temperature than in the case of $1800 \mathrm{~B}$ LCs. All of these LC mixtures were synthesized at the Military University of Technology (Warsaw, Poland).

a)

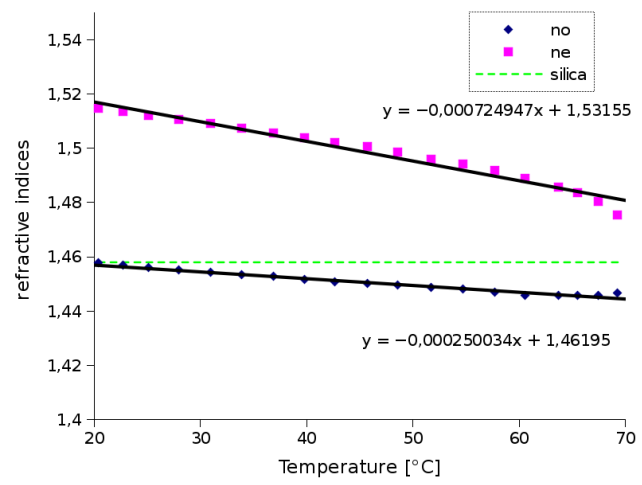

Fig. 1. Refractive indices as a function of temperature for 1550A (a) and 1800B (b) liquid crystal.

As a host structure the solid-core 070124 PCF (Fig. 2) manufactured at the Maria Curie Sklodowska University (UMCS, Lublin, Poland) was used. This PCF is characterized by 3 rings of holes and it has $3.9 \mu \mathrm{m}$ core diameter. The solid-core PCF used in this experiment was $\sim 90 \mathrm{~cm}$ long and it was infiltrated with 1800B LC (section of $\sim 5 \mathrm{~cm})$. The second one was also about $90 \mathrm{~cm}$ long but it was infiltrated with $1550 \mathrm{~A} \mathrm{LC} \mathrm{(section} \mathrm{of} \sim 3 \mathrm{~cm}$ ). 


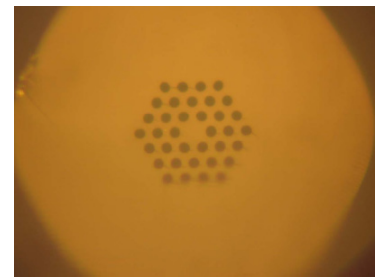

Fig. 2. Cross-sections of the photonic crystal fibers with 3 rings of holes (070124)

Because of the PCF filling method by capillary action, it is supposed that the orientation of LC in PCF is planar. The PLCF under investigation was connected face-to-face with an SM fiber and glued together in a capillary. Then the PLCF was put between two electrodes (Fig. 3). As a light source a laser diode was used operating on a wavelength of $633 \mathrm{~nm}(5 \mathrm{~mW})$ and a tunable laser (Laser Tunics-Plus 1500-1640nm) with the $1540 \mathrm{~nm}$ wavelength. The experimental setup (Fig. 4) consisted of a temperature control module (Fig. 5), Function Generator $(1 \mu \mathrm{Hz}-10 \mathrm{MHz})$ with an amplifier and two electrodes for an electric field generating, PAT 9000B Polarimeter as a detector.

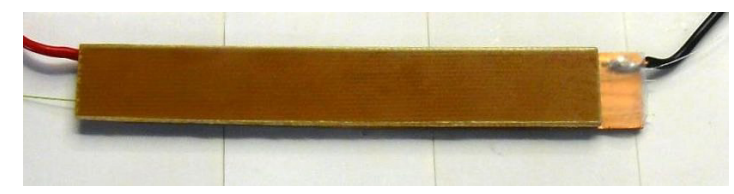

Fig. 3. PLCF sample put between two electrodes.

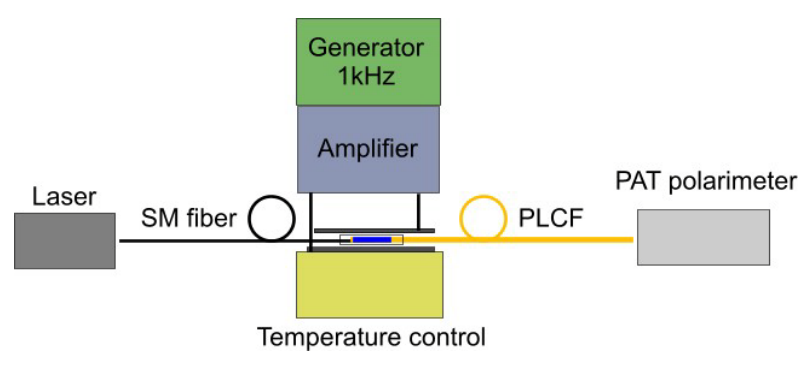

Fig. 4. The experimental set-up.

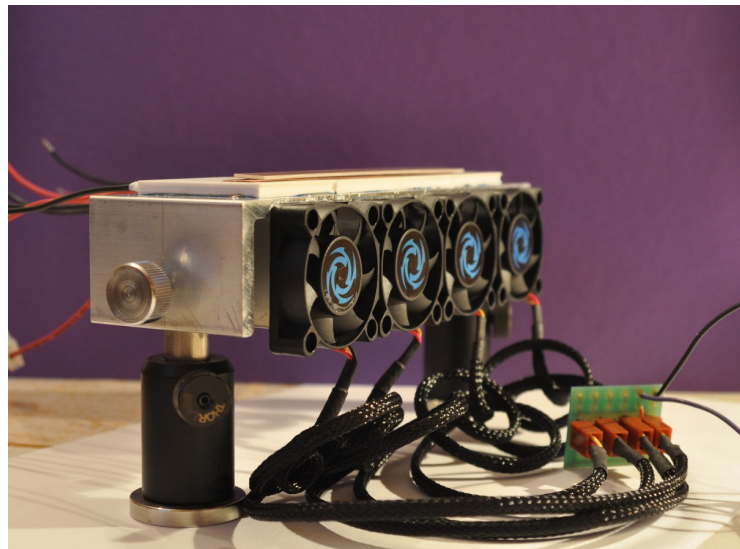

Fig. 5. A temperature control unit based on Peltier modules, radiator and fans.

In this experiment the 070124 PCF filled with the $1800 \mathrm{~B}$ LC was used. In this case the LC section was about $5 \mathrm{~cm}$. As a light source a laser diode was used operating on a wavelength of $633 \mathrm{~nm}$. The operating temperature was $61^{\circ} \mathrm{C}$. The total losses of this fiber sample equaled $-35 \mathrm{~dB}$. The state of polarization was changing under the influence of an electric field. A $2 \pi$ phase shift was observed at $1 \mathrm{kHz}$ frequency and $2.3 \mathrm{~V} / \mu \mathrm{m}$ value of an electric field (Fig. 6)

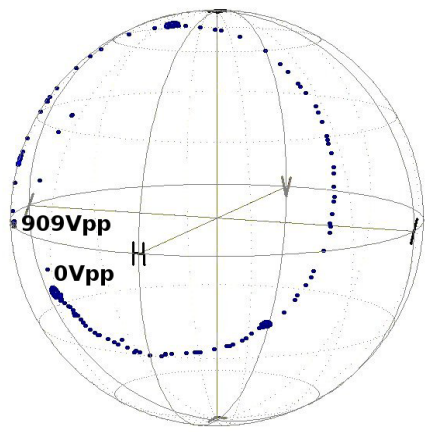

Fig. 6. Changes in the polarization state under the influence of an electric field visualized on the Poincare sphere for 070124 PCF filled with $1800 \mathrm{~B}$ (LC section of $5 \mathrm{~cm})(1 \mathrm{kHz}, 909 \mathrm{Vpp})$.

The second sample consisted of the 070124 PCF filled with the 1550A wherein the LC section was $3 \mathrm{~cm}$-long. As a light source a tuning laser with the $1540 \mathrm{~nm}$ wavelength was used. The operating temperature was $30^{\circ} \mathrm{C}$. The total losses of this fiber sample were $-30 \mathrm{~dB}$. The state of polarization was changing under the influence of an electric field. A $2 \pi$-phase shift was observed at a frequency of $1 \mathrm{kHz}$ and $2 \mathrm{~V} / \mu \mathrm{m}$ value of an electric field (Fig. 7). 


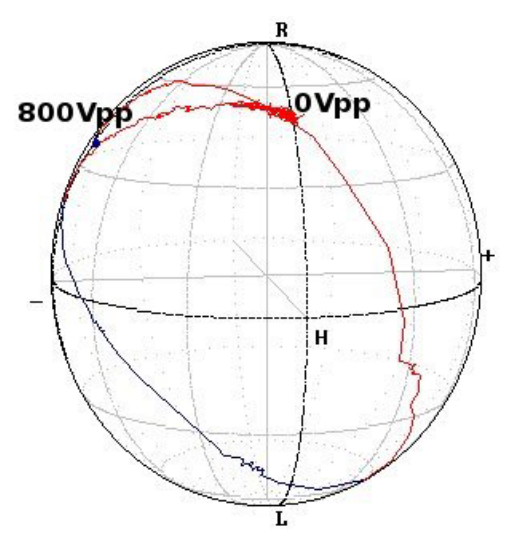

Fig. 7. Changes in the polarization state under the influence of an electric field visualized on the Poincare sphere for 070124 PCF filled with the $1550 \mathrm{~A}$ (LC section of $3 \mathrm{~cm})(1 \mathrm{kHz}, 800 \mathrm{Vpp})$.

Because of low attenuation and wide change of phase the best experimental results were obtained for the 070124 PCF filled with the $1550 \mathrm{~A}$ LC. It is related with optical properties of the 1550A: higher birefringence and mTIR mechanism temperature close to and even below room temperature.

Changes in the polarization state observed in the Poincare sphere were related to a change in the phase between both orthogonal components of the modes which are propagating through the photonic liquid crystal fiber.

The observation of polarization state changes makes it possible to determine the range of phase birefringence changes caused by electric field growth. To calculate the change of phase birefringence the following formula was used:

$$
\Delta \mathrm{B}(\mathrm{E})=\frac{\Delta \varphi(\mathrm{E})}{2 \pi} \frac{\lambda}{\mathrm{L}}
$$

where $\triangle B(E)$ is a change of the PLCF phase birefringence caused by the change of an electric field value, $\mathrm{L}$ is the length of the PLCF placed in the electric field and $\Delta \varphi(E)$ can be easily determined from the change in the position of a point on the Poincare sphere (one full turn is equivalent to a $2 \pi$-phase shift). The maximum range of change in the value of phase birefringence for the 070124 PCF filled with the $1800 \mathrm{~B} \mathrm{LC}$ is $1.3 \cdot 10^{-5}$ (1) and for the $070124 \mathrm{PCF}$ filled with the $1550 \mathrm{~A}$ is $5.1 \cdot 10^{-5}$ (1) (for the empty $070124 \mathrm{PCF}$ the phase birefringence is $\left.5 \cdot 10^{-6}\right)$. The $1800 \mathrm{~B}$ LC is characterized by low birefringence so the phase birefringence change range is smaller than for the $1550 \mathrm{~A}$. Increasing the filling length of LC in PCFs should additionally increase the phase change range.
The experimental results obtained suggest a possible application of PLCFs as a dynamically tunable fiber-optic phase shifter.

This work was supported by the Polish Ministry of Science and Education under the grant N517 056535and by the MISTRZ Programme of the Polish Science Foundation.

\section{References}

[1] B. Eggleton, Ch. Kerbage, P. Westbrook, R. Windeler, A. Hale, Opt Exp. 9(13), 698 (2001).

[2] P. St. J. Russell, Science 299, 358 (2003).

[3] C. Knight, Nature 424, 847, (2003).

[4] T.T. Larsen, A. Bjarklev, D.S. Hermann, and J. Broeng, Opt. Exp. 11, 2589 (2003)

[5] C. Zhang, G.Kai, Z. Wang, Y. Liu, T. Sun, S. Yuan, X. Dong, Opt. Lett. 30, 2703 (2005).

[6] T. Alkeskjold, J. Lægsgaard, A. Bjarklev, D. Hermann, A. Anawati, J. Broeng, J. Li, and S.-T. Wu, Opt. Exp. 12, 5857 (200).

[7] T. R. Woliński, M. M. Tefelska, M. S. Chychłowski, K. Godyń, R. Dąbrowski, J. Wójcik, T. Nasiłowski, and H. Thienpont, Mol. Cryst. Liq. Cryst., 502, 220 (2009).

[8] T.T. Alkeskjold, A. Bjarklev, Opt. Lett. 32, 1707 (2007).

[9] D.C. Zografopoulos, E.E. Kriezis, T.D. Tsiboukis, Opt. Exp. 14, 914 (2006).

[10] T.R. Woliński, S. Ertman, P. Lesiak, A. W. Domański, A. Czapla, R. Dąbrowski, E. Nowinowski-Kruszelnicki, J. Wójcik, OptoElectr. Rev. 14, 329 (2006).

[11] M.M. Tefelska, M.S. Chychłowski, T.R. Woliński, R. Dąbrowski, J. Wójcik, Phot. Lett. of Poland 1(2), 97 (2009).

[12] T.R. Wolinski, P. Lesiak, A.W. Domanski, S.Ertman, K. Szaniawska, Mol. Cryst. Liq. Cryst. 454, 735 (2006). 